\title{
Susceptibility of rainbow trout Oncorhynchus mykiss, Atlantic salmon Salmo salar and coho salmon Oncorhynchus kisutch to experimental infection with sea lice Lepeophtheirus salmonis
}

\author{
Mark D. Fast ${ }^{1,2}$, Neil W. Ross ${ }^{2, *}$, Ahmed Mustafa ${ }^{1, * *}$, David E. Sims ${ }^{1}$, Stewart C. \\ Johnson $^{2}$, Gary A. Conboy ${ }^{3}$, David J. Speare ${ }^{3}$, Gerald Johnson ${ }^{3}$, John F. Burka ${ }^{1}$ \\ ${ }^{1}$ Department of Anatomy and Physiology, Atlantic Veterinary College, University of Prince Edward Island, Charlottetown, \\ Prince Edward Island C1A 4P3, Canada \\ ${ }^{2}$ Institute for Marine Biosciences, National Research Council of Canada, 1411 Oxford Street, Halifax, Nova Scotia B3H 3Z1, \\ Canada \\ ${ }^{3}$ Department of Pathology and Microbiology, Atlantic Veterinary College, University of Prince Edward Island, \\ Charlottetown, Prince Edward Island C1A 4P3, Canada
}

\begin{abstract}
Physiological, immunological and biochemical parameters of blood and mucus, as well as skin histology, were compared in 3 salmonid species (rainbow trout Oncorhynchus mykiss, Atlantic salmon Salmo salar and coho salmon O. kisutch) following experimental infection with sea lice Lepeophtheirus salmonis. The 3 salmonid species were cohabited in order to standardize initial infection conditions. Lice density was significantly reduced on coho salmon within 7 to $14 \mathrm{~d}$, while lice persisted in higher numbers on rainbow trout and Atlantic salmon. Lice matured more slowly on coho salmon than on the other 2 species, and maturation was slightly slower on rainbow trout than on Atlantic salmon. Head kidney macrophages from infected Atlantic salmon had diminished respiratory burst and phagocytic capacity at 14 and $21 \mathrm{~d}$ post-infection (dpi), while infected rainbow trout macrophages had reduced respiratory burst and phagocytic capacities at $21 \mathrm{dpi}$, compared to controls. The slower development of lice, coupled with delayed suppression of immune parameters, suggests that rainbow trout are slightly more resistant to lice than Atlantic salmon. Infected rainbow trout and Atlantic salmon showed increases in mucus lysozyme activities at $1 \mathrm{dpi}$, which decreased over the rest of the study. Mucus lysozyme activities of infected rainbow trout, however, remained higher than controls over the entire period. Coho salmon lysozyme activities did not increase in infected fish until 21 dpi. Mucus alkaline phosphatase levels were also higher in infected Atlantic salmon compared to controls at 3 and 21 dpi. Low molecular weight (LMW) proteases increased in infected rainbow trout and Atlantic salmon between 14 and 21 dpi. Histological analysis of the outer epithelium revealed mucus cell hypertrophy in rainbow trout and Atlantic salmon following infection. Plasma cortisol, glucose, electrolyte and protein concentrations and hematocrit all remained within physiological limits for each species, with no differences occurring between infected and control fish. Our results demonstrate that significant differences in mucus biochemistry and numbers of L. salmonis occur between these species.
\end{abstract}

KEY WORDS: Skin mucus $\cdot$ Lysozyme $\cdot$ Sea lice $\cdot$ Protease $\cdot$ Alkaline phosphatase $\cdot$ Salmonids $\cdot$ Immunity

*Corresponding author. E-mail: neil.ross@nrc.ca

${ }^{* *}$ Present address: Department of Biology, Indiana University, Purdue University at Fort Wayne, 2101 E. Coliseum Boulevard, Fort Wayne, Indiana, 46805-1499, USA

\section{INTRODUCTION}

In recent years, epizootics of sea lice Lepeophtheirus salmonis, a common marine ectoparasitic copepod of 
salmonids, have resulted in heavy losses and millions of dollars worth of damage to aquaculture throughout the northern hemisphere (Pike 1989, MacKinnon 1997). L. salmonis feed on mucus, skin and blood of salmonids causing osmoregulatory stress and death in extreme cases (Grimnes \& Jakobsen 1996, Björn \& Finstad 1997). Attempts at controlling this parasite with chemotherapeutants have yet to produce long-term protection without creating toxicity or extended tissue-residence times. It is our expectation that through a better understanding of host-parasite relationships we may develop more effective control measures for the future.

Host species differences in susceptibility towards sea lice infection has previously been reported (Johnson \& Albright 1992a, Dawson et al. 1997). Johnson \& Albright (1992a,b) observed that when coho, chinook and Atlantic salmon were infected at the same level, coho salmon quickly lost their Lepeophtheirus salmonis. Atlantic salmon, a commercially important species on both coasts of Canada, is more susceptible and often exhibits lesions and decreased immune function due to L. salmonis infection (Grimnes \& Jacobsen 1996, Bowers et al. 2000, Mustafa et al. 2000). Atlantic salmon have shown changes in blood physiology such as increased hematocrit, glucose and cortisol concentrations (Bowers et al. 2000) and in the skin and gill epithelia such as increased apoptosis, necrosis and leukocyte infiltration (Nolan et al. 1999) in response to pre-adult and adult $L$. salmonis.

Mucus covering the fish's epidermal surface is the first line of defense against invading pathogens. The epidermal layer is also important in this aspect as it secretes the layers of mucus important to host defense mechanisms as well as providing mechanical protection. Enzymes and other proteins located within the mucus, such as lysozyme, have bactericidal activities (Dalmo et al. 1997). Alkaline phosphatase is a lysosomal enzyme suggested to have a possible protective role in fishes during the first stages of wound-healing (Iger \& Abraham 1994). Elevated alkaline phosphatase levels in mucus or mucus secretory cells have been shown to increase under parasitic infection in Atlantic salmon (Ross et al. 2000) and under stressful living conditions in carp (Iger \& Abraham 1997). Paradoxically, proteases found in the skin and mucus may arise from either host innate immunity or parasite virulence. Increased protease activities and a corresponding rate of bacterial lysis in eel skin have been observed following environmental stressors (Aranishi et al. 1998, Aranishi 2000). Increased mucus protease levels have also been reported in Atlantic salmon following Lepeophtheirus salmonis infection (Ross et al. 2000). However, the increased protease activities in Atlantic salmon following infection appear to have originated from L. salmonis, not the host fish (Firth et al. 2000).
A co-habitation study was conducted to further explore the difference in susceptibility of different host species and to determine physiological and immunological changes in blood and biochemical and histological changes at the skin surface between infected and control fishes. The differences in the response of a putatively resistant species (coho salmon) and that of more susceptible hosts (rainbow trout and Atlantic salmon) may give insight into the mechanisms by which Lepeophtheirus salmonis are rejected. A parallel comparison of normal mucus parameters in these 3 species has been published separately (Fast et al. 2002).

\section{MATERIALS AND METHODS}

Fishes and their maintenance. The fishes used for this study were yearling (S1) seawater-adapted rainbow trout, Atlantic salmon and coho salmon. Rainbow trout (Kamloops strain) and Atlantic salmon (Saint John River strain) were obtained from the Department of Fisheries and Oceans (DFO) certified hatcheries in Pictou, Nova Scotia and Murray River, Prince Edward Island, respectively. Coho salmon were obtained through the research facilities of Aqua Health Limited, Charlottetown, Prince Edward Island, originally from the DFO Big Qualicum hatchery, Vancouver, British Columbia.

All fishes were adapted to seawater by gradually increasing the salinity with Instant Ocean ${ }^{\circledR}$ (Aquarium Systems, Mentor, Ohio) over a $2 \mathrm{wk}$ period to $30 \pm 2 \mathrm{ppt}$ salinity at $10 \pm 1^{\circ} \mathrm{C}$. Two weeks following transfer to seawater, 160 fish of each species were randomly distributed to 2 control and 2 treatment tanks and acclimated for an additional $2 \mathrm{wk}$. Dissolved oxygen levels were maintained at $8 \mathrm{ppm}$, photoperiod was $14 \mathrm{~h}$ light:10 h dark, and the fishes were fed to satiation twice daily. At the start of the study, rainbow trout, Atlantic salmon and coho salmon had average weights $( \pm \mathrm{SD})$ of $188 \pm 40,113 \pm 23$ and $40 \pm 10 \mathrm{~g}$, respectively.

Lepeophtheirus salmonis culture and laboratory infection. Infective copepodids were grown in the laboratory and fishes were infected with Lepeophtheirus salmonis following the methods described by Mustafa et al. (2000). Approximately 100 to 150 infective copepodids/fish were added to the designated test tanks under reduced water volume (ca. 40 to $60 \mathrm{~kg} \mathrm{~m}^{-3}$ ) and flow for $12 \mathrm{~h}$. Supplemental oxygen was added to maintain tanks at $8 \mathrm{ppm}$, and $70 \mu \mathrm{m}$ mesh was placed over outflows to prevent loss of copepodids. Control tanks were subjected to the same reduced volume and flow as in test tanks without addition of copepodids.

Sampling. On Days 0 (prior to infection), 1, 3, 7, 14, and $21 \mathrm{~d}$ post infection (dpi), 5 fish of each species from each tank were sampled. The fishes were kept off-feed 
for $24 \mathrm{~h}$ prior to sampling. Each fish was placed into a separate 101 bucket containing a lethal dose of anesthetic (200 $\mathrm{mg} \mathrm{l}^{-1}$; MS-222, Syndel Laboratories, Vancouver, British Columbia) and individually bagged with $10 \mathrm{ml}$ of $0.1 \mathrm{M}$ ammonium bicarbonate $(\mathrm{pH} 7.8)$ buffer to collect mucus as described by Ross et al. (2000). Length, breadth, and weight were measured immediately after mucus collection.

Blood was extracted from the caudal vein ( 3 to $5 \mathrm{ml}$ ) with 1 or $5 \mathrm{~cm}^{3}$ syringes and 16 or $21 \mathrm{G}$ needles flushed with heparin (Sigma). Head kidneys from each fish were removed aseptically for macrophage assays. Finally, the fishes were individually examined and Lepeophtheirus salmonis were counted and staged. When sufficient numbers were available, a minimum of $30 \mathrm{~L}$. salmonis were staged from each species on each day. Lice counts were corrected for size of the fishes using condition factor (i.e. body shape) and multiplying it by an estimation of epidermal surface area (i.e. available area for infection) as shown below:

$$
\begin{aligned}
& \text { Area- corrected lice counts }= \\
& \text { no. of lice } \div\left(\frac{\text { weight }}{\text { length }}\right) \times(\text { length } \times \text { breadth } \times 2)
\end{aligned}
$$

Analysis of blood samples. Blood samples were spun for $5 \mathrm{~min}$ at $4000 \times \mathrm{g}$. Plasma was decanted and stored at $-80^{\circ} \mathrm{C}$ until further use. Plasma cortisol (Coat-ACount ${ }^{\circledR}$ RIA, Diagnostic Products Corp.), glucose (colorimetric glucose oxidase method), sodium, potassium, and chloride levels were determined for each fish (indirect ion selective electrode [ISE] method) by the Atlantic Veterinary College Diagnostic Services Unit following the methods described in Bowers et al. (2000). Because of the small volumes of blood obtained for coho salmon, not all of the physiological parameters could be recorded from the blood of each individual.

Analysis of kidney samples for macrophage function. Isolation of head kidney macrophages and detection of respiratory burst activity and phagocytosis were performed following the methods described by Mustafa et al. (2000). Briefly, head kidneys were removed from the fishes and placed in Leibovitz-15 (L15, Sigma) medium containing $2 \%$ fetal calf serum (FCS, Sigma). Samples were macerated and centrifuged at $1000 \times g$. Cells were resuspended in L-15 containing $0.1 \%$ FCS and centrifuged to wash thecells (this step was done twice). A trypan blue (Sigma) exclusion test was used to test cells for viability. Macrophage respiratory-burst activity was determined by reduction of nitro-blue tetrazolium (NBT, Sigma) by leucocytes stimulated with phorbol myristate acetate (Sigma). Duplicate $100 \mu$ l aliquots were incubated in a moist chamber on glass slides for $90 \mathrm{~min}$ at $18^{\circ} \mathrm{C}$. The slides were then rinsed with phosphate-buffered saline
(PBS) and incubated for a further 15 min at $18^{\circ} \mathrm{C}$ with NBT. Following incubation slides were examined under $100 \times$ magnification and 100 cells were counted to determine the proportion of activated cells.

Macrophage phagocytic activity determined the proportion of phagocytic cells that were able to take up formalin-killed bacteria, Yersinia ruckeri. Y. ruckeri $\left(10^{7}\right.$ in PBS) were added to slides containing adherent macrophages and incubated for $60 \mathrm{~min}$ at $18^{\circ} \mathrm{C}$. Slides were then washed with PBS, air-dried, fixed in methanol and stained with Diff-quick ${ }^{\circledR}$ (Leukostat stain kit, Fisher). Following incubation, slides were examined under 100× magnification and 100 cells were counted to determine the percentage of macrophage cells containing $\geq 5$ bacteria.

Analysis of mucus samples. Prior to analysis, mucus samples were thawed on ice and centrifuged at $9300 \times$ $g$ for 2 min. Protein concentrations of the resulting supernatants were determined by the dye binding method (Bradford 1976) using a BioRad (Hercules, California) kit. All assays were run on a Thermomax microplate reader (Molecular Devices).

Alkaline phosphatase activity was determined through incubation of mucus samples with $4 \mathrm{mM} p$ nitrophenol phosphate (Sigma) in $100 \mathrm{mM}$ ammonium bicarbonate, $\mathrm{pH} 7.8,1 \mathrm{mM} \mathrm{MgCl}_{2}$ (Fisher) following the methods given in Ross et al. (2000). One unit (U) of activity was defined as the amount of enzyme required to release $1 \mu \mathrm{mol}$ of $p$-nitrophenol product in $1 \mathrm{~min}$. The extinction coefficient of $p$-nitrophenol in the microplate wells was experimentally determined at $405 \mathrm{~nm}$.

Lysozyme activity was determined using a turbidometric assay (Ross et al. 2000). Briefly, mucus samples were lyophilized, resuspended in an equal volume of $40 \mathrm{mM}$ sodium phosphate and then incubated in a 96well plate with lyophilized Micrococcus lysodeikticus cells (Sigma, $0.3 \mathrm{mg} \mathrm{ml}^{-1}$ ) at $30^{\circ} \mathrm{C}$ for $30 \mathrm{~min}$. The initial rate of reaction was used to calculate the activity, with $1 \mathrm{U}$ of activity being defined as the amount of enzyme that catalyzed a decrease in absorbance $(450 \mathrm{~nm})$ of $0.001 \mathrm{~min}^{-1}$.

Protease activities were determined using the azocasein hydrolysis assay and zymography described by Firth et al. (2000). The azocasein hydrolysis assay involved incubation of mucus samples with azocasein substrate (Sigma) for $19 \mathrm{~h}$ at $30^{\circ} \mathrm{C}$ in $100 \mathrm{mM}$ ammonium bicarbonate, $\mathrm{pH} 7.8$, precipitation with trichloroacetic acid $4.5 \%(\mathrm{w} / \mathrm{v})$, and centrifugation at $15000 \times g$ for $5 \mathrm{~min}$ (Firth et al. 2000). The resultant supernatant was added to a 96-well plate containing an equal volume of $0.5 \mathrm{M} \mathrm{NaOH}$ and $\mathrm{OD}$ (450 nm) determined using a microplate reader. One unit of activity was defined as the amount of enzyme causing an increase in absorbance of 0.001 OD units per $19 \mathrm{~h}$. 
For zymography, mucus samples were diluted 1:1 with $4 \%$ SDS, 125 mM Tris-HCl, pH 6.8, glycerol $20 \%$ and equal amounts of protein added to $12 \%$ polyacrylamide gels containing $0.1 \%$ gelatin. Following electrophoresis, the gels were washed 3 times at $4^{\circ} \mathrm{C}$ with $2.5 \%$ Triton X-100, 50 mM Tris- $\mathrm{HCl}, \mathrm{pH} 7.5$, and incubated $\left(30^{\circ} \mathrm{C}\right)$ for $19 \mathrm{~h}$ with the same buffer containing $50 \mathrm{mM} \mathrm{MgCl}, 6.25 \mathrm{mM} \mathrm{CaCl}_{2}$. Following the incubation, gels were stained in $0.1 \%$ amido black in $\mathrm{MeOH} / \mathrm{H}_{2} \mathrm{O} / \mathrm{AcOH}(45: 45: 10)$ for $1 \mathrm{~h}$ and destained with $\mathrm{MeOH} / \mathrm{H}_{2} \mathrm{O} / \mathrm{AcOH}$ (50:48:2) until the desired contrast was obtained.

Histological analysis. Skin samples, $4 \mathrm{~cm}$ long and $3 \mathrm{~cm}$ wide, were dissected from 5 fish of each species on each sampling day (except Day 0). Skin was removed from the mid-body on the left side, where a line drawn from the middle of the dorsal fin would intersect with the lateral line. This site was selected to assess indirect changes to skin associated with the stress of sea lice infection, as lice typically attach to other areas of the body (Johnson \& Albright 1992a,b). The skin was fixed in $10 \%$ buffered neutral formalin for $48 \mathrm{~h}$ at $4^{\circ} \mathrm{C}$, cut in half along the long axis, trimmed of damaged tissue on the sides, paraffin-embedded, sectioned at a thickness of $5 \mu \mathrm{m}$, and hematoxylin and eosinstained. Histology preparations were measured for thickness of the outer layer of the epidermis and for mucus cell density and size. The epidermis of all 3 species is composed of undulating scale folds. The scale fold length was used as an arbitrary unit for measure (Fig. 1). The outer epidermis layer was measured for maximal thickness, average thickness (determined as total cross-sectional area divided by length), frequency of mucus cells (expressed as no. of mucus cells per $100 \mu \mathrm{m}$ surface length) as an expression of mucus cell hyperplasia, and diameter of the largest mucus cell as a measure of mucus cell hypertrophy.

The original skin sample was cut in half prior to embedding; both halves were measured for 5 contiguous inter-fold lengths, producing 10 replicates of each variable per fish. These were averaged, and the averages for each of the 5 fish per species per day were subjected to statistical analysis.

Statistical analysis. Statistical analyses were performed using SigmaStat for Windows Version 2.0 (SPSS). One-way analysis of variance (ANOVA) was used to test for a tank effect. No significant differences were observed between tanks, and data were pooled into 2 groups (control and infected). A 2-way ANOVA was used to compare infected and control fish over time within a species. A 3-way ANOVA was used to test for significant differences among condition (infected and control fish), species and time. Multiple range tests were carried out using Tukey's HSD tests on all data. Differences were considered significant when $\mathrm{p}<0.05$. All data were checked for normality and non-normal data was transformed using $(\sqrt{x})$ or $\log (x+1)$ transformations. All values shown, are means \pm SEM, except in the case of population weights where SD were used. Spearman rank-order correlations were used to determine whether there were correlations between lice counts and enzyme activities. The same correlation statistics were employed to observe whether or not there was a correlation between any of

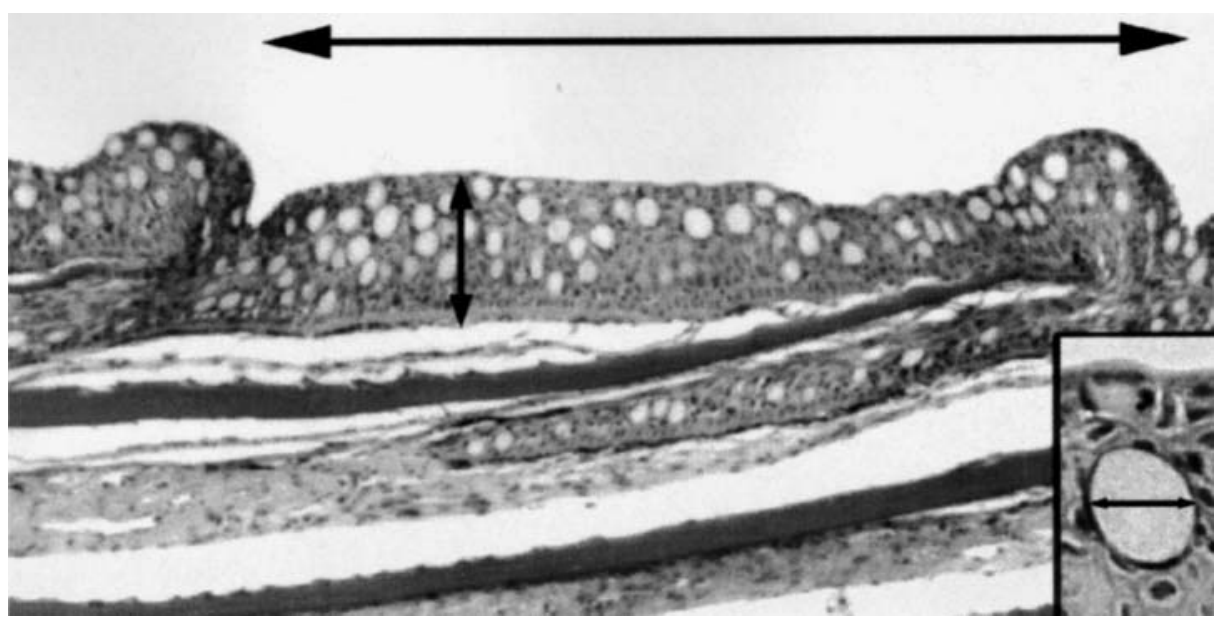

Fig. 1. Skin samples used for histological analysis. These were cut along their mid-line, and then the 2 halves were embedded in paraffin. From both of the resulting skin sections, 5 inter-scale distances (horizontal arrow) were analyzed for maximal thickness of epidermis (vertical arrow), average thickness of epidermis (calculated as cross-sectional area divided by length), number of mucus cells (no. $100 \mathrm{\mu m}^{-1}$ surface) to measure for mucus cell hyperplasia, and the width of the largest mucus cell (inset) to measure for mucus cell hypertrophy. The values for 10 sub-samples were averaged for each fish, and the averages pooled for comparison of 5 fish per species per day 


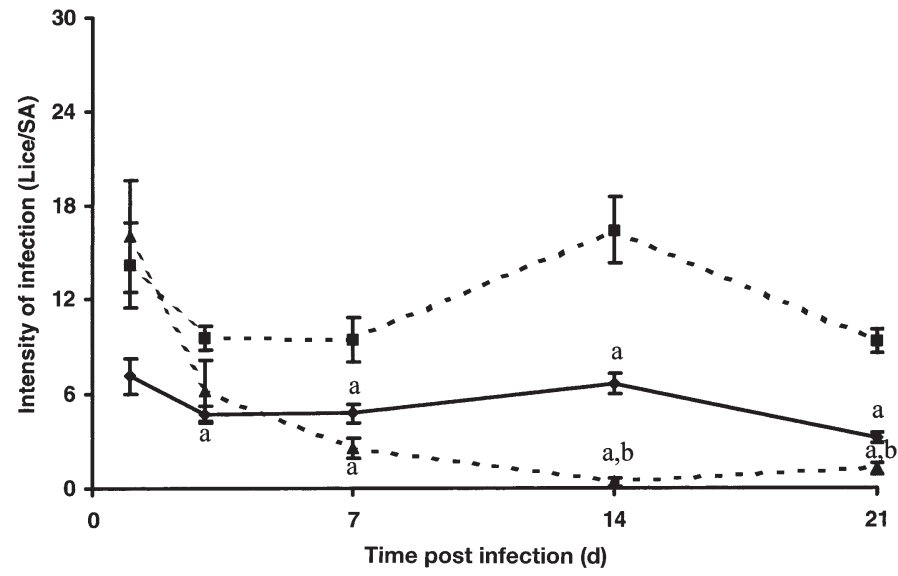

Fig. 2. Lepeophtheirus salmonis. Mean $( \pm$ SEM) intensity of infection on rainbow trout Oncorhynchus mykiss (•), Atlantic salmon Salmo salar (घ) and coho salmon O. kisutch (\$) at various days post-infection (dpi), corrected for surface area of fish available to louse. a: lice counts significantly lower than on Atlantic salmon for that particular day; b: lice counts significantly lower than on rainbow trout on that particular day. Lice/SA: lice per sample

the following: lysozyme activity, alkaline phosphatase activity, protease activity, cortisol concentrations and diameter of the largest mucus cell. The presence or absence of protease bands, as determined by zymography, were compared between host species and over time using a chi-squared analysis.

\section{RESULTS}

\section{Intensity of infection}

When the numbers of Lepeophtheirus salmonis per fish were corrected to account for the available surface area on each fish, no significant differences in initial infection intensity were observed between the 3 species. Rainbow trout had a significantly lower level of infection than Atlantic salmon at 3, 7, 14 and $21 \mathrm{dpi}$. Coho salmon had a significantly lower level of infection than both rainbow trout and Atlantic salmon at 14 and $21 \mathrm{dpi}$ (Fig. 2). The number of L. salmonis on coho salmon decreased significantly from 1 to $14 \mathrm{dpi}$, with only 3 lice found on a total of 10 fish by 14 dpi. By 21 dpi the mean number of $L$. salmonis had increased to about 1 louse per fish on coho salmon. The number of lice decreased on rainbow trout and Atlantic salmon from 14 to $21 \mathrm{dpi}$.

At 1 and $3 \mathrm{dpi}$, all sea lice found on infected fishes were in the infective copepodid stage, except 1 . One pre-adult male was found on a coho salmon from an infected tank on Day 1. At 7 dpi, all sea lice were Chalimus I-stage larvae on coho salmon, while rainbow trout had some Chalimus II larvae and Atlantic salmon had the highest proportion of Chalimus II (Fig. 3). By Day 14 , approximately $20 \%$ of the lice had matured to the Chalimus IV stage larvae on rainbow trout and Atlantic salmon, with coho salmon having only Stage III chalimus larvae. By 21 dpi, lice were mostly preadults on all species and only male pre-adults were found on coho salmon (Fig. 3).

\section{Blood physiology}

Throughout this experiment, cortisol concentrations ranged between 6.3-38.5, 6.51-40.2 and 16.3$51.2 \mathrm{nmol} \mathrm{l}^{-1}$ for rainbow trout, Atlantic salmon and coho salmon, respectively. There were no significant differences in plasma cortisol concentrations between infected and control fish for any of the host species, except in rainbow trout at $1 \mathrm{dpi}$ : at $1 \mathrm{dpi}$, infected rainbow trout had significantly higher cortisol concentrations compared to controls (Fig. 4); plasma cortisol concentrations of infected fish were significantly higher at 1 dpi compared to subsequent sampling days.
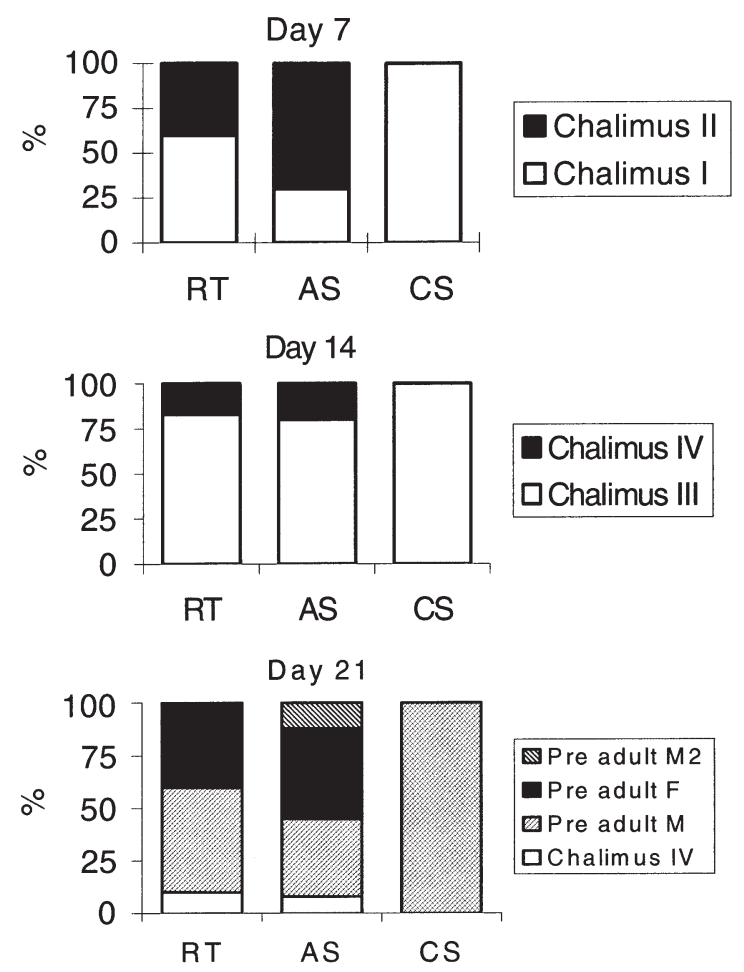

Fig. 3. Lepeophtheirus salmonis. Life stages on rainbow trout Oncorhynchus mykiss (RT), Atlantic salmon Salmo salar (AS) and coho salmon $O$. kisutch (CS) at 7, 14 and 21 dpi. Number of lice staged for each day: $\mathrm{n}=50$ for RT, $\mathrm{n}=30$ for AS and $\mathrm{n}=20$ for coho salmon (except when there were too few lice on coho, i.e. 14 dpi $(n=3)$ and 21 dpi $(n=10)$ 


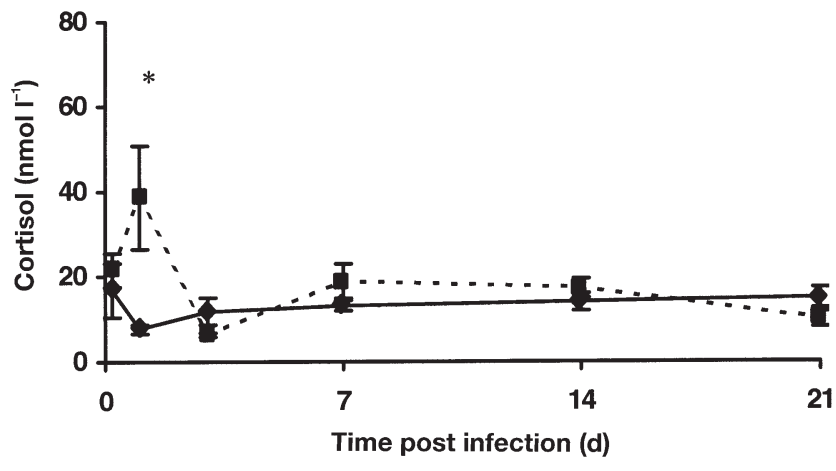

Fig. 4. Oncorhynchus mykiss. Comparison of mean $( \pm \mathrm{SEM})$ plasma cortisol levels between Lepeophtheirus salmonisinfected (匹) and non-infected $(\bullet)$ rainbow trout over time

Because of the small volume of plasma obtained from coho salmon, the following parameters were measured for rainbow trout and Atlantic salmon only. Plasma sodium, potassium and chloride concentrations were not significantly different between infected and control fish or between rainbow trout and Atlantic salmon in any of the samples. Sodium, chloride and glucose concentrations were between 150-165, 120-135 and 2-8 $\mathrm{mmol} \mathrm{l}^{-1}$ in rainbow trout and Atlantic salmon over the course of the experiment, respectively (data not shown).
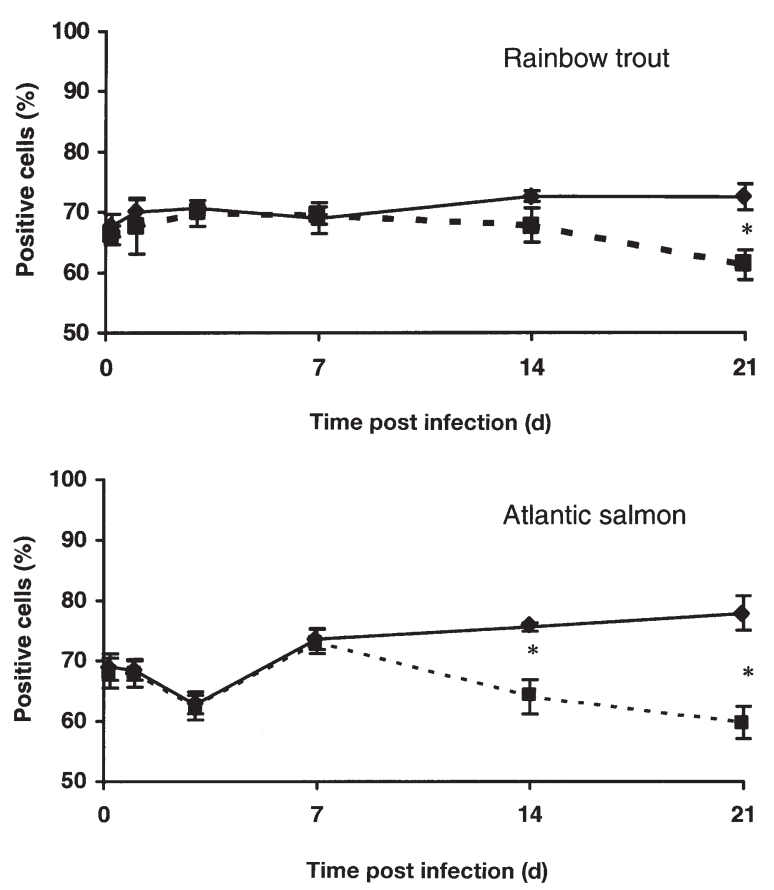

Fig. 5. Mean $( \pm$ SEM) respiratory burst activity in the macrophage from the head kidney of Lepeophtheirus salmonisinfected (匹) and non-infected (*) fishes over time. * Significant differences from control on that day $(p<0.05)$
Throughout the experiment, rainbow trout hematocrit values ranged from 40 to $47 \%$, Atlantic salmon ranged from 45 to $55 \%$ and coho salmon from 48 to $60 \%$ (data not shown). There were no significant differences in hematocrit levels between control and infected fish in any of the host species. However, coho salmon had significantly higher hematocrit values than rainbow trout and Atlantic salmon on each sampling day. Hematocrit values peaked in Atlantic and coho salmon at 3 dpi at 55 and $60 \%$ respectively. Despite this peak, the general trend in all 3 species was a decrease in hematocrit levels over the course of the experiment. Mean plasma protein concentrations showed no significant differences between infected and control fish, however rainbow trout had significantly higher plasma protein concentrations in comparison to both Atlantic and coho salmon. In rainbow trout (infected and controls combined) blood protein concentrations peaked at 0 and $21 \mathrm{dpi}$ at 7.1 and $6.8 \mathrm{~g}$ $100 \mathrm{ml}^{-1}$, respectively. In Atlantic and coho salmon (infected and controls combined), mean plasma protein concentrations peaked on Day 0 at 5.3 and $6.0 \mathrm{~g}$ $100 \mathrm{ml}^{-1}$, respectively (data not shown).

\section{Respiratory burst activity and phagocytic capacity}

There were no significant differences in respiratoryburst activity (Fig. 5) or phagocytic capacity (Fig. 6) of macrophages isolated from infected and control rainbow trout until $21 \mathrm{dpi}$, when a significant suppression was observed in the infected group. There was significant suppression of respiratory-burst activity (Fig. 5) and in phagocytic capacity (Fig. 6) in infected Atlantic salmon at 14 and 21 dpi. There was no significant difference in respiratory-burst activities and phagocytic capacities between control and Lepeophtheirus salmonis-infected coho salmon at any time.

\section{Mucus biochemistry}

Alkaline phosphatase (AP) activities in the mucus of rainbow trout ranged from 0.67 to $7.31 \mathrm{U} \mathrm{mg}^{-1}$ protein and there were no significant differences between infected and control fish over the course of the experiment. Alkaline phosphatase activities were significantly higher in infected Atlantic salmon mucus at 3 and 21 dpi in comparison to controls (Fig. 7). Although AP activities were higher in the mucus of infected fish compared to controls at 7 and $14 \mathrm{dpi}$, these data were not significantly different $(p=0.09$ and $p=0.1$, respectively). Rainbow trout mucus had significantly higher AP activities than that of the other 2 species throughout the experiment, except compared to Atlantic 

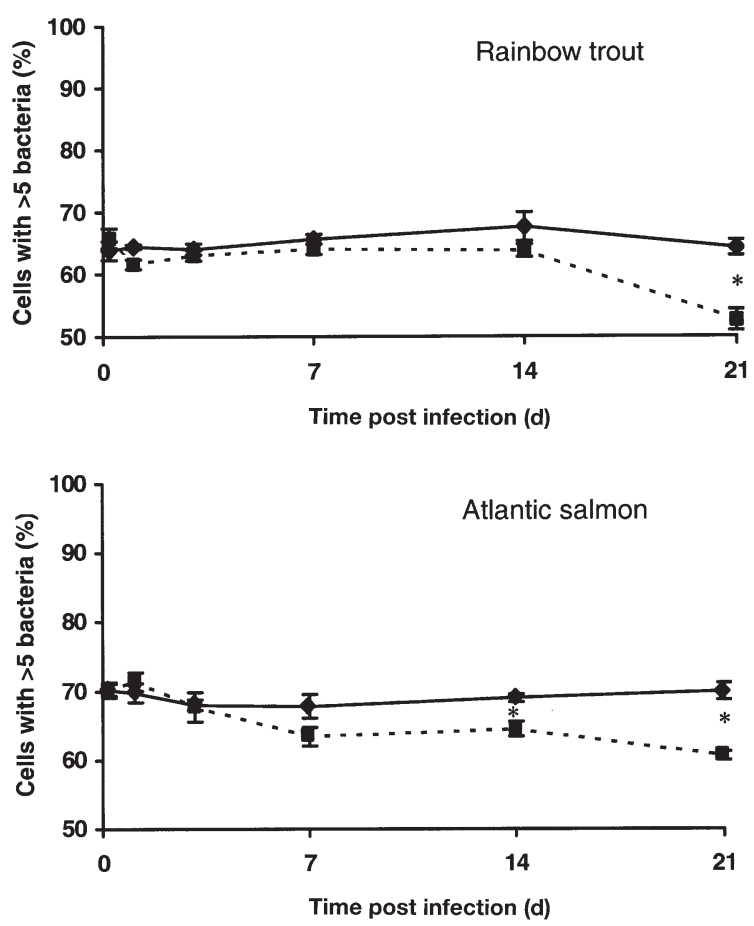

Fig. 6. Oncorhynchus mykiss and Salmo salar. Mean $( \pm$ SEM) phagocytic activity in the macrophage from the head kidney of Lepeophtheirus salmonis-infected (घ) and non-infected $(\bullet)$ fishes over time. * Significant differences from control on that day $(\mathrm{p}<0.05)$

salmon controls on Day 0 (data not shown). Coho salmon mucus showed no significant differences in AP activities between infected and control fish, and these levels ranged from 0.13 to $1.22 \mathrm{U} \mathrm{mg}^{-1}$ of protein throughout the experiment.

Lysozyme activities peaked at 1 dpi and were low over the rest of the experiment in the mucus of infected rainbow trout and Atlantic salmon. Rainbow trout controls showed maximum activity on Day 0 in mucus lysozyme activity (Fig. 8). Rainbow trout also showed significantly higher mucus lysozyme activities in infected fish compared to controls on all days postinfection (Fig. 8). Lysozyme activities were significantly higher in mucus of infected Atlantic salmon compared to uninfected fish at $1 \mathrm{dpi}$ but there were no significant differences on any other days (Fig. 8). Lysozyme activities were significantly higher in infected coho salmon mucus at 21 dpi (Fig. 8) when lysozyme activity increased 10 -fold. There was a high degree of individual variation, since lysozyme activity was high in 6 of 10 fish, while 4 fish showed very little lysozyme activity. In general, rainbow trout mucus had significantly higher lysozyme activities than the other 2 species throughout the study, except when compared with 21 dpi infected coho salmon.
Quantitative assessment of protease activity, as determined with the azocasein hydrolysis assay, showed no significant difference between infected and control fish in rainbow trout and Atlantic salmon. Mean mucus protease activity ranged from 0.011 to $0.069 \mathrm{U} \mathrm{mg}^{-1}$ protein in rainbow trout and Atlantic salmon. Mucus protease activity was higher in infected Atlantic salmon than in controls on all days after lice infection; however the differences were not significant (data not shown). Only at $21 \mathrm{dpi}$ did coho salmon show significant differences between mucus consistency protease activity in control and infected fish, with control coho salmon mucus having significantly higher protease activity compared to infected coho mucus (Fig. 9).

Assessment of mucus protease profiles by zymography showed no difference between infected and control fish mucus LMW protease activity in coho salmon (Fig. 10). Infected rainbow trout and Atlantic salmon both showed the presence of a series of low molecular weight proteases (15 to $20 \mathrm{kDa}$ ) by the later days of the trial. In rainbow trout, the series of LMW protease bands differed from the single band observed in controls. The number of infected rainbow trout having these multiple bands of LMW proteases significantly increased at $21 \mathrm{dpi}(\mathrm{p}<0.01)$ (Fig. 10). Atlantic salmon showed a similar increase in the number of infected fish, with the same low-molecular weight proteases in infected fish at both $14(\mathrm{p}<0.05)$ and $21 \mathrm{dpi}(\mathrm{p}<0.01)$ (Figs. $10 \& 11$ ). Ten out of 10 infected rainbow trout (at $21 \mathrm{dpi}$ ) and Atlantic salmon (at 14 and $21 \mathrm{dpi}$ ) showed the presence of multiple bands in the LMW range, while no control fish in either species showed the presence of multiple bands in this range on any day.

The mucus from infected and control rainbow trout, Atlantic and coho salmon were assessed for their abil-

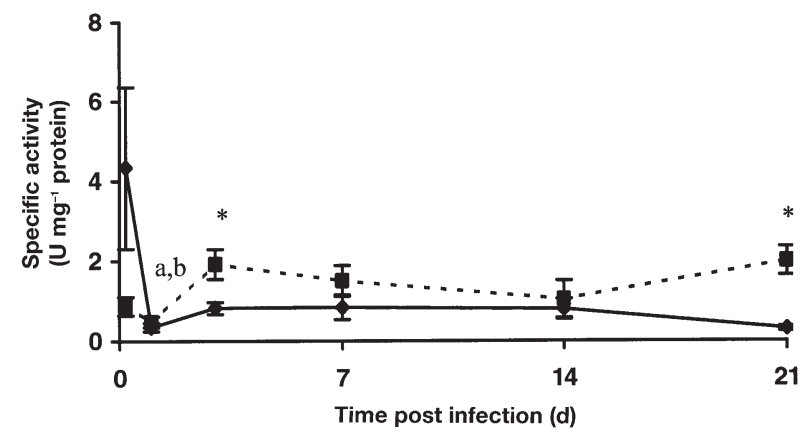

Fig. 7. Salmo salar. Mean ( \pm SEM) specific activity of alkaline phosphatase in mucus of Lepeophtheirus salmonis-infected $(\varpi)$ and non-infected $(\bullet)$ Atlantic salmon. * Significant differences from control on that day $(p<0.05)$. a: 1 d post-infection (dpi) levels significantly lower in controls than levels at $3 \mathrm{dpi}$; b: 1 dpi levels significantly lower in infected fish than levels at 7 and 21 dpi 
ity to inhibit the activity of bovine trypsin. No inhibition of trypsin activity was observed in any mucus samples (data not shown).

\section{Histology}

The outer epidermis of Atlantic salmon was significantly thinner, with fewer layers of epithelial cells, and fewer mucus cells than rainbow trout or coho salmon. There were no significant differences in epidermal
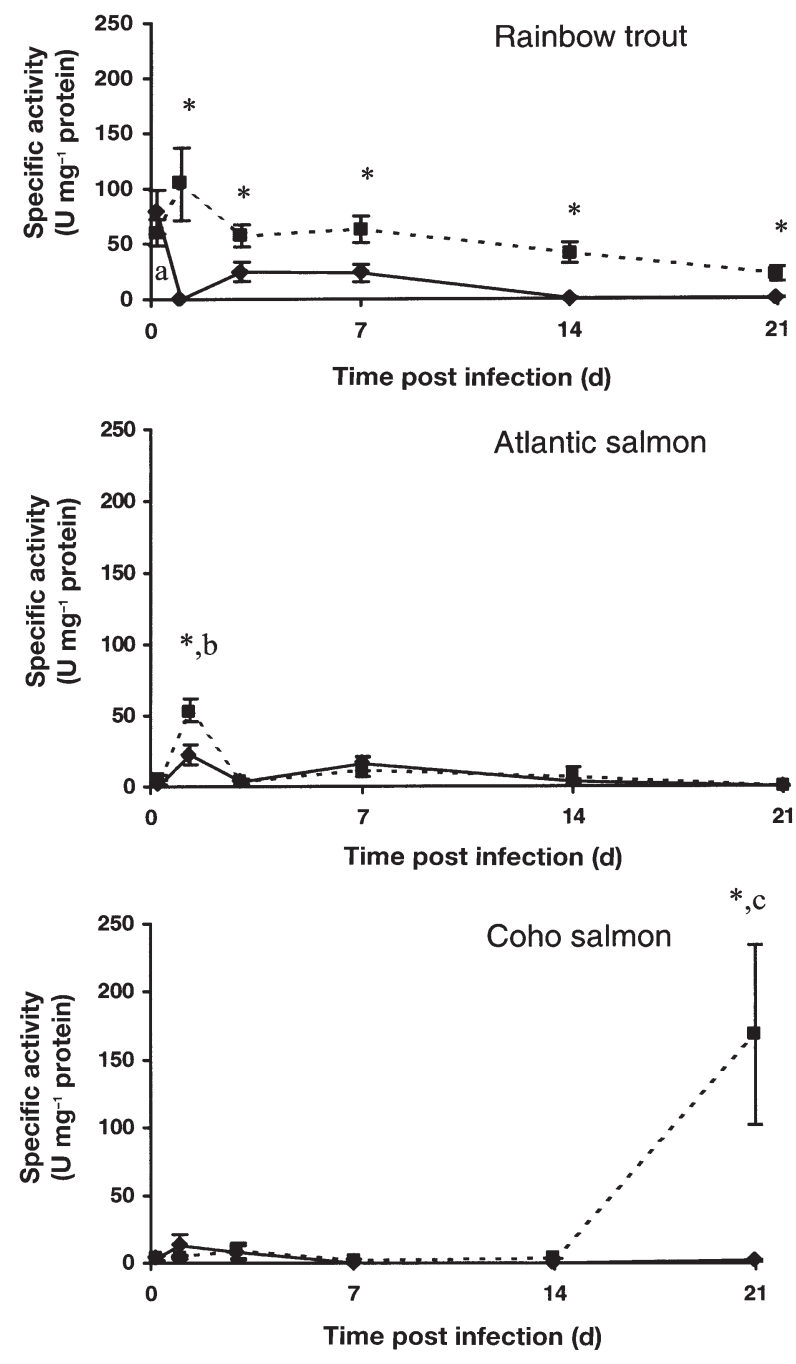

Fig. 8. Oncorhynchus mykiss, Salmo salar and O. kisutch. Mean $( \pm \mathrm{SE})$ specific activity of lysozyme in mucus of Lepeophtheirus salmonis-infected (๘) and non-infected $(\bullet)$ fishes of 3 salmonid species over time. * Significant differences from control on that day $(p<0.05)$. a: prior to infection $(0 \mathrm{dpi})$ mucus lysozyme activities significantly higher in controls than on all other days. b: mucous lysozyme activities at 1 dpi significantly higher in infected fishes than at 3, 7, 14 and $21 \mathrm{dpi}$; c: mucous lysozyme levels at $21 \mathrm{dpi}$ significantly higher in infected fishes than on all other days

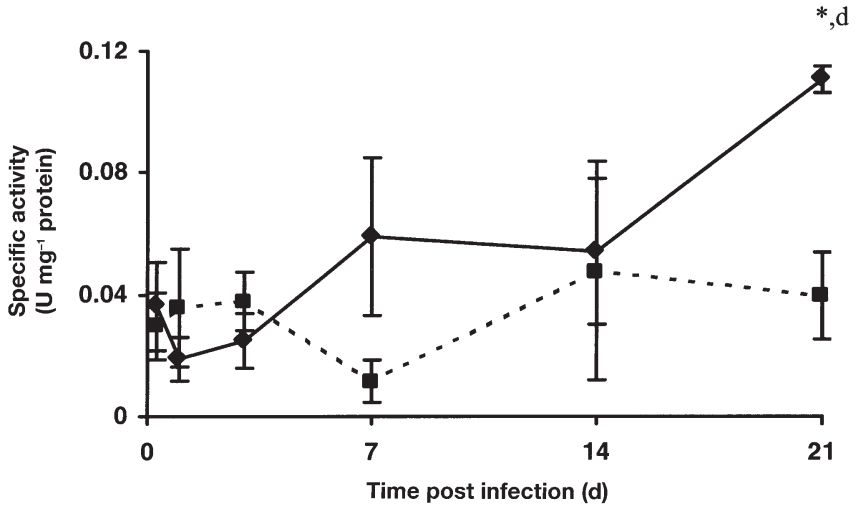

Fig. 9. Oncorhynchus mykiss. Mean $( \pm \mathrm{SE})$ protease activity in the mucus of Lepeophtheirus salmonis-infected (घ) and noninfected $(\bullet)$ coho salmon. Protease activity was determined by azocasein hydrolysis at $30^{\circ} \mathrm{C}$ and results are presented as total color produced in $19 \mathrm{~h}$. * Significant differences from control on that day $(p<0.05)$. d: mucus protease activities at $21 \mathrm{dpi}$

significantly higher in controls than on all other days

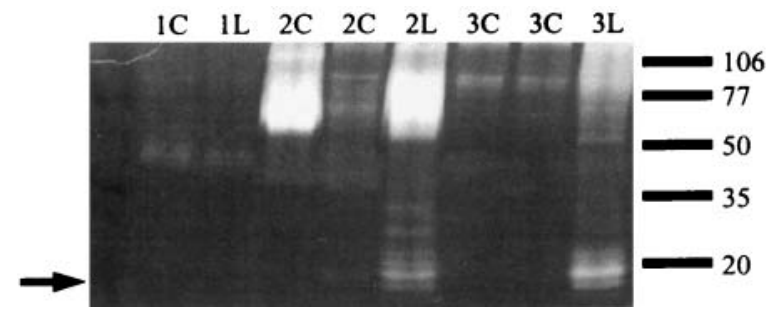

Fig. 10. Oncorhynchus kisutch (1), O. mykiss (2) and Salmo salar (3). Zymogram of protease activity in the mucus of control and infected coho salmon, rainbow trout and Atlantic salmon at $21 \mathrm{dpi}$. Each well contained $3 \mu \mathrm{g}$ of mucus protein and samples are representative of each species. C: controls and L: Lepeophtheirus salmonis-infected fishes. Numbers alongside each gel indicate molecular weights $(\mathrm{kDa})$.

$\rightarrow$ : multiple bands of low molecular weight proteases

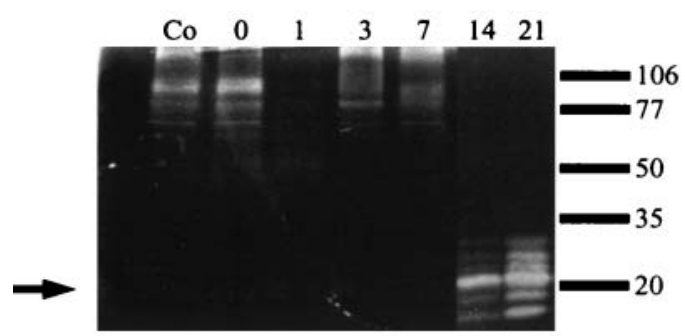

Fig. 11. Salmo salar. Zymogram of protease activity in the mucus of control (Co) and Lepeophtheirus salmonis-infected $(0,1,3,7,14,21$ dpi) Atlantic salmon. Numbers at the top of each gel indicate dpi on which each fish was sampled. Numbers alongside each gel indicate molecular weights $(\mathrm{kDa})$. Each well contains $3 \mu \mathrm{g}$ of mucus protein and samples are representative of Atlantic salmon samples for each day. The control sample was also representative of control samples throughout the study. $\rightarrow$ : multiple bands of low molecular weight proteases 
thickness or number of mucus cells between control and infected fish in any species. Mucus cell hypertrophy was observed at 1 and 21 dpi in infected rainbow trout compared to controls (Table 1). Infected Atlantic salmon had significant mucus cell hypertrophy at $1 \mathrm{dpi}$ (Table 1). Infected coho salmon had significantly greater mucus cell hypertrophy compared to controls at 14 dpi (Table 1), but the difference appeared to be caused by a fluctuation in the control fish, not those exposed to Lepeophtheirus salmonis. When singleblinded slides were randomly examined, no significant alterations indicative of acute inflammation or other forms of damage were observed.

\section{Correlation of data}

Correlations between lice densities and enzyme activities or mucus cell hypertrophy in the 3 species studied were not apparent. There were also no correlations between lysozyme, protease or alkaline phosphatase activities in the 3 species studied. There was a strong positive correlation between cortisol and mucus lysozyme activity in rainbow trout over the entire study (Spearman $r=0.634, p=0.03$ ). As well, mucus lysozyme activities had a positive correlation with plasma cortisol in Atlantic salmon over the entire study (Spearman $r=0.6550, p=0.02$ ).

\section{DISCUSSION}

All 3 species were infected to a similar degree following addition of Lepeophtheirus salmonis copepodids. The loss of L. salmonis by coho salmon by $14 \mathrm{dpi}$ was similar to data of Johnson \& Albright (1992a,b), who reported rejection of $L$. salmonis by naïve coho salmon between 10 and $21 \mathrm{dpi}$. In contrast, L. salmonis levels on rainbow trout and Atlantic salmon remained relatively high throughout the experiment, consistent with results of previous studies (Johnson \& Albright 1992a, Grimnes \& Jakobsen 1996, Bowers et al. 2000,
Mustafa et al. 2000). As reported in other studies, we noted an increase in L. salmonis levels on both rainbow trout and Atlantic salmon at 14 dpi (Björn \& Finstad 1997). This increase is most probably attributable to the difficulty in counting or loss of L. salmonis from the host when they are in the early life stages. Decreases in L. salmonis infection on rainbow trout and Atlantic salmon, at the later stages of infection, are most probably attributable to loss from the host of the mobile preadults. Transfer of L. salmonis between hosts is demonstrated by the appearance of pre-adult males on coho salmon at $21 \mathrm{dpi}$. Under laboratory and field conditions, movement of pre-adult $L$. salmonis has previously been observed between different hosts (Jakobsen 1993) and different host species (Bruno \& Stone 1990). Gonzalez et al. (2000) has also shown movement of pre-adult Caligus flexispina from rainbow trout to coho salmon under laboratory conditions.

Lepeophtheirus salmonis matured slowest on coho salmon followed by rainbow trout and then Atlantic salmon. Differences in L. salmonis growth rates, between chinook salmon and Atlantic salmon have been previously reported (Johnson 1993).

A single pre-adult male was recorded on 1 infected coho salmon at $1 \mathrm{dpi}$. This was most probably due to transfer (via splashing) from infected fish that were held in an adjacent tank (part of another study). As all water flow into the tanks passed through sand filters and no Lepeophtheirus salmonis were found on control fishes throughout the experiment, this was considered an isolated incident of negligible effect on the study.

In this study we found decreased macrophage activity in rainbow trout and Atlantic salmon infected with Lepeophtheirus salmonis, similar to data reported by Mustafa et al. (2000). However, Mustafa et al.'s study, cortisol levels were elevated and the fish had much higher numbers of L. salmonis. It has been suggested that pre-adult and adult stages of L. salmonis have a greater impact on the physiology of fishes than earlier developmental stages by Grimnes \& Jakobsen 1996, Björn \& Finstad 1997, and Bowers et al. 2000, who observed increased plasma cortisol, hematocrit and

Table 1. Oncorhynchus mykiss, Salmo salar and O. kisutch. Mean (SEM) diameter of largest mucous cell in the skin epithelium of Lepeophtheirus salmonis-infected fish and non-infected fish over time. ${ }^{*}$ Significant differences from control on that day $(\mathrm{p}<0.05){ }_{i}{ }^{* *}$ significant differences from control on that day $(\mathrm{p}<0.01)$. dpi: days post infection

\begin{tabular}{|c|c|c|c|c|c|c|}
\hline \multirow{2}{*}{$\begin{array}{l}\text { Sampling day } \\
\text { (dpi) }\end{array}$} & \multicolumn{2}{|c|}{ Rainbow trout } & \multicolumn{2}{|c|}{ Atlantic salmon } & \multicolumn{2}{|c|}{ Coho salmon } \\
\hline & Control & Infected & Control & Infected & Control & Infected \\
\hline 1 & $22.2 \pm 2.2$ & $27.0 \pm 2.3^{* *}$ & $10.6 \pm 4.6$ & $18.3 \pm 3.8^{*}$ & $19.4 \pm 5.3$ & $17.3 \pm 4.9$ \\
\hline 3 & $26.6 \pm 1.5$ & $24.2 \pm 1.9$ & $15.6 \pm 3.2$ & $15.6 \pm 0.6$ & $23.8 \pm 3.11$ & $20.6 \pm 2.5$ \\
\hline 7 & $27.0 \pm 1.6$ & $25.8 \pm 1.1$ & $15.6 \pm 1.7$ & $12.0 \pm 2.3^{*}$ & $20.0 \pm 5.2$ & $22.1 \pm 2.4$ \\
\hline 14 & $22.8 \pm 2.7$ & $23.2 \pm 0.8$ & $17.2 \pm 2.4$ & $16.0 \pm 4.9$ & $17.2 \pm 3.3$ & $22.0 \pm 2.4$ \\
\hline 21 & $25.3 \pm 2.1$ & $28.7 \pm 2.1^{*}$ & $16.4 \pm 3.3$ & $18.0 \pm 3.9$ & $19.8 \pm 2.1$ & $21.7 \pm 1.0$ \\
\hline
\end{tabular}


electrolyte levels in infected fishes, again at much higher L. salmonis levels than in the current study. Our data suggest that lower numbers of L. salmonis may also cause decreased immune function in the absence of a cortisol response. The immunosuppressive effects of L. salmonis appeared to begin in Atlantic salmon prior to the pre-adult stage and may be due to increased damage of feeding as L. salmonis get larger, or perhaps to immunosuppressive secretions from L. salmonis. While this is the first reported evidence of immunosuppressive effects prior to the pre-adult stage, the presence of L. salmonis-derived trypsin, which is a potential virulence factor, has been reported in host mucus as early as 3 dpi (Ross et al. 2000). Trypsin has been linked to feeding in other arthropod parasites as well (Bowles et al. 1988). As few as 3 to 10 pre-adult and adult L. salmonis per fish have been shown to cause changes in the epithelial structure of the skin and gill (Nolan et al. 1999). This could be due to L. salmonis enzyme secretions, which assist in breaking down this barrier (Firth et al. 2000). Once $L$. salmonis biomass increases to a critical level on a fish, or L. salmonis reaches the pre-adult stage, these secretions may also have an immunosuppressive effect, after which we begin to see depressed macrophage function in the fish (Mustafa et al. 2000). The lack of changes in coho salmon macrophage function is probably due to the rapid loss of $L$. salmonis from the host.

The LMW proteases observed in infected rainbow trout (at $21 \mathrm{dpi}$ ) and Atlantic salmon (at 14 and $21 \mathrm{dpi}$ ) are similar to those trypsins observed in the mucus of Lepeophtheirus salmonis-infected Atlantic salmon (Firth et al. 2000, Ross et al. 2000). Although L. salmonis densities on Atlantic salmon in this experiment were similar to those in the study of Ross et al. (2000), we did not observe multiple bands of LMW proteases until $14 \mathrm{dpi}$. This may be due to our use of larger fish (113.1 vs 56.9 g, by Ross et al. 2000), which could decrease the ratio of $L$. salmonis secretory/excretory volume:host mucus.

Retarded maturation and lower relative abundance of Lepeophtheirus salmonis on rainbow trout than Atlantic salmon, coupled with the observations that the depressed macrophage function and presence of multiple bands of LMW proteases occurred later in rainbow trout (21 dpi) than in Atlantic salmon (14 dpi), leads us to the conclusion that Atlantic salmon are a more susceptible host than rainbow trout. This has not been shown previously under laboratory conditions. However, Jackson et al. (1997) observed lower numbers of L. salmonis on rainbow trout than on Atlantic salmon kept in adjacent cages along the west coast of Ireland.

The timing of increases in AP activity in infected Atlantic salmon mucus are interesting in that early in the infection Lepeophtheirus salmonis are preparing for their first moult on the host (copepodid to Chalimus I). This occurs around $3 \mathrm{dpi}$, and AP increases may be due to epidermal excavation by the copepodid for filament attachment (Jones et al. 1990). Later increases in AP (21 dpi) coincide with the first appearance of preadults, more aggressive feeders than the earlier stages, which can move over wide body areas, possibly causing more irritation. Iger \& Abraham (1994) observed strong AP reactions in mucus and pavement cells of carp 30 min after wounding. Ross et al. (2000) observed increased AP activities in the mucus of Atlantic salmon infected with high numbers of L. salmonis; however, no AP increases in Atlantic salmon mucus were observed during a low-level infection. While the source of increased AP activity is still uncertain, it is probably due to a combination of host-derived AP following wounding and secretion/excretions from L. salmonis (Fast et al. in press). No relationship between AP activity and $L$. salmonis infection, however, was found in rainbow trout or coho salmon.

Electrolyte, cortisol, glucose and protein concentrations and hematocrit readings all remained within established physiological resting ranges for these salmonids (Wedermeyer et al. 1990), even when Lepeophtheirus salmonis reached the pre-adult stage. The higher cortisol concentrations at $1 \mathrm{dpi}$ (in all fishes) were most probably a result of crowding, as the tank volumes were reduced during the $12 \mathrm{~h}$ infection period for sea lice attachment. Despite the interspecies differences over time, both rainbow trout and Atlantic salmon showed similar patterns of increased mucus lysozyme activity and generalized mucus cell hypertrophy shortly after infection with L. salmonis (1 dpi). These may be part of these species' responses to initial L. salmonis introduction and/or stress during crowding, which however are not capable of fighting off the infection. Rainbow trout, which exhibited significantly higher plasma cortisol concentrations in infected fish compared to controls, may be more sensitive to the double stressor under cohabitation than the other 2 species studied. Additive effects of stressors have previously been reported in fish administered cortisol and infected with Argulus spp. (Ruane et al. 1999, van der Salm et al. 2000) and in fish infected with $L$. salmonis and then undergoing crowding stress (Nolan et al. 2000). Cortisol and lysozyme activities showed a strong positive correlation in this study in both rainbow trout and Atlantic salmon. Infected rainbow trout, however, maintained significantly higher mucus lysozyme activities compared to controls throughout the study. The increase in mucus lysozyme observed late in the infection in coho salmon could be attributed to a fish response to reinfection with pre-adults. 
Since there were no significant differences between resistant and susceptible species' blood physiology, even in coho salmon during rejection of Lepeophtheirus salmonis, it seems likely that the differences occur in the mucus and epithelial layers of the host fish. Furthermore, the speed with which coho salmon rejected the $L$. salmonis infection leads to the hypothesis that the resistance factors are part of an innate immunity of coho salmon. Interestingly, even parasitic copepod species with more generalized host ranges than L. salmonis, such as Caligus flexispina, exhibit low-level infections on coho salmon compared to other host species (Gonzalez et al. 2000). This suggests there may be innate factors in coho salmon mucus that provide protection against ectoparasitic copepods in general. There may also be factors in the mucus of rainbow trout and Atlantic salmon (as well as other susceptible hosts) that encourage L. salmonis infection and growth as opposed to the inhibitory factors in coho salmon mucus that discourage L. salmonis infection. Factors present in the mucus layer of these salmonid species, as well as their integumentary organization, may ultimately determine whether hosts are susceptible or resistant to $L$. salmonis or other copepod infections. Future research will focus on $L$. salmonis responses to mucus from different hosts and examine factors that provide resistance in an attempt to better understand the mechanisms of host selection by L. salmonis.

Acknowledgements. The authors would like to thank Anping Wang, Kara Firth, Pablo Gonzalez-Alanis, Kim Niblett and Cheryl Wartman for their help on sampling days and with assays. The help of Dr. Michael Brimacombe was essential in the statistical design to analyse our data. Wayne Petley and Lee Dawson of the Aquatic Animal Facility of AVC helped in fish maintenance. The authors would also like to thank Heritage Aquaculture Inc., Atlantic Silver, Jail Island, Stolt Sea Farms and Ronnie Hawkins, for their assistance during lice collection. This research was funded by the Salmon Health Consortium and a Collaborative Research and Development Grant from NSERC and NRC, Canada.

\section{LITERATURE CITED}

Aranishi F (2000) High sensitivity of skin cathepsins L and B of European eel (Anguilla anguilla) to thermal stress. Aquaculture 182:209-213

Aranishi F, Mano N, Nakane M, Hirose H (1998) Epidermal response of the Japanese eel to environmental stress. Fish Physiol Biochem 19:197-203

Björn PA, Finstad B (1997) The physiological effects of salmon lice infection on sea trout post-smolts. Nord J Freshw Res 73:60-72

Bowers JM, Burka JF, Mustafa A, Speare DJ, Conboy GA, Sims DE, Brimacombe M (2000) The effects of a single experimental challenge of sea lice, Lepeophtheirus salmonis, on the stress response of Atlantic salmon, Salmo salar. J Fish Dis 23:165-172

Bowles VM, Carnegie PR, Sandeman RM (1988) Characterization of proteolytic and collagenolytic enzymes from the larvae of Lucilia cuprina, the sheep bowfly. Aust J Biol Res 41:269-278

Bradford MM (1976) A rapid and sensitive method for the quantitation of microgram quantities of protein utilizing the principle of protein-dye binding. Anal Biochem 72: $248-254$

Bruno DW, Stone J (1990) The role of saithe, Pollachius virens L., as a host for the sea lice, Lepeophtheirus salmonis Krøyer and Caligus elongatus Nordmann. Aquaculture 89: 201-207

Dalmo RA, Ingebrigtsen K, Bogwald J (1997) Nonspecific defence mechanisms in fish, with particular reference to the reticuloendothelial system (RES). J Fish Dis 20: 241-273

Dawson LHJ, Pike AW, Houlihan DF, McVicar AH (1997) Comparison of the susceptibility of sea trout (Salmo trutta) and Atlantic salmon (Salmo salar) to sea lice Lepeophtheirus salmonis (Krøyer, 1837) infections. ICES J Mar Sci 54:1129-1139

Fast MD, Sims DE, Burka JF, Mustafa A, Ross NW (2002) Skin morphology and humoral non-specific defence parameters of mucus and plasma in rainbow trout, coho and Atlantic salmon. Comp Biochem Physiol A 132:645-657

Fast MD, Burka JF, Johnson SC, Ross NW (in press) Enzymes released from Lepeophtheirus salmonis in response to mucus from different salmonids. J Parasitol

Firth KJ, Johnson SC, Ross NW (2000) Characterization of proteases in the skin mucus of Atlantic salmon (Salmo salar) infected with the salmon louse (Lepeophtheirus salmonis) and in the whole-body louse homogenate. J Parasitol 86:1199-1205

Gonzalez L, Carvajal J, George-Nascimento M (2000) Differential infectivity of Caligus flexispina (Copepoda, Caligidae) in 3 farmed salmonids in Chile. Aquaculture 183: $13-23$

Grimnes A, Jakobsen PJ (1996) The physiological effects of salmon lice infection on post-smolt of Atlantic salmon. J Fish Biol 48:1179-1194

Iger Y, Abraham M (1994) The process of skin healing in experimentally wounded carp. J Fish Biol 36:21-437

Iger Y, Abraham M (1997) Rodlet cells in the epidermis of fish exposed to stressors. Cell Tissue Res 29:431-438

Jackson D, Deady S, Leahy Y, Hassett D (1997) Variations in parasitic caligid infestations on farmed salmonids and implications for their management. ICES J Mar Sci 54: $1104-1112$

Jakobsen P (1993) Lice infestation of wild salmonid populations in Norway. In: Meldon J (ed) Aquaculture in Ireland-towards sustainability. An Taisce Publication, Dublin, p 75-76

Johnson SC (1993) A comparison of development and growth rates of Lepeophtheirus salmonis (Copepoda: Caligidae) on naïve Atlantic (Salmo salar) and Chinook (Oncorhynchus tshawytscha) salmon. In: Boxshall GA, Defaye D (eds) Pathogens of wild and farmed fish: sea lice. Ellis Horwood, Toronto, p 68-83

Johnson SC, Albright, LJ (1992a) Comparative susceptibility and histopathology of the response of naive Atlantic, chinook and coho salmon to experimental infection with Lepeophtheirus salmonis (Copepoda: Caligidae). Dis Aquat Org 14:179-193

Johnson SC, Albright, LJ (1992b) Effects of cortisol implants on the susceptibility and the histopathology of the responses of naive coho salmon Oncorhynchus kisutch to experimental infection with Lepeophtheirus salmonis (Copepoda: Caligidae). Dis Aquat Org 14:195-205

Jones MW, Sommerville C, Bron J (1990) The histopathology 
associated with the juvenile stages of Lepeophtheirus salmonis on the Atlantic salmon, Salmo salar L. J Fish Dis 13:303-310

MacKinnon BM (1997) Sea lice: a review. World Aquacult 28: $5-10$

Mustafa A, MacWilliams C, Fernandez A, Matchett K, Conboy G, Burka JF (2000) Effects of sea lice (Lepeophtheirus salmonis Krøyer, 1837) infestation on macrophage functions in Atlantic salmon (Salmo salar L.). Fish Shellfish Immunol 10:47-59

Nolan DT, Reilly P, Wendelaar Bonga SE (1999) Infection with low numbers of the sea louse Lepeophtheirus salmonis induces stress-related effects in postsmolt Atlantic salmon (Salmo salar). Can J Aquat Sci 56:947-959

Nolan DT, Ruane NM, van der Hejden Y, Quabius ES, Costelloe J, Wendelaar Bonga SE (2000) Juvenile Lepeophtheirus salmonis (Krøyer) affect the skin and gills of rainbow trout Oncorhynchus mykiss (Walbaum) and the host response to a handling procedure. Aquac Res 31: 823-833

Editorial responsibility: Wolfgang Körting,

Hannover, Germany
Pike AW (1989) Sea lice-major pathogens of farmed Atlantic salmon. Parasitol Today 5:291-297

Ross NW, Firth KJ, Wang A, Burka JF, Johnson SC (2000) Changes in hydrolytic enzyme activities of naïve Atlantic salmon (Salmo salar) skin mucus due to infection with the salmon louse (Lepeophtheirus salmonis) and cortisol implantation. Dis Aquat Org 41:43-51

Ruane NM, Nolan DT, Rotllant J, Tort L, Balm PHM, Wendelaar Bonga SE (1999) Modulation of the response of rainbow trout (Oncorhynchus mykiss Walbaum) to confinement, by an ectoparasitic (Argulus foliaceus L.) infestation and cortisol feeding. Fish Physiol Biochem 20:43-51

van der Salm AL, Nolan DT, Spanings FAT, Wendelaar Bonga SE (2000) Effects of infection with the ectoparasite Argulus japonicus (Thiele) and administration of cortisol on cellular proliferation and apoptosis in the epidermis of common carp, Cyprinus carpio L., skin. J Fish Dis 23:173-184

Wedermeyer GA, Barton BA, McLeay DJ (1990) Stress and acclimation. In: Shreck CB, Moyle PB (eds) Methods for fish biology. American Fisheries Society, Bethesda, p 451-490

Submitted: December 11, 2001; Accepted: April 10, 2002 Proofs received from author(s): September 20, 2002 